\title{
Application of recycled plastic in flat roofs
}

\author{
Radim Smolka ${ }^{1, *}$, and Jindřich Sobotka ${ }^{1}$ \\ ${ }^{1}$ Brno University of Technology, Faculty of Civil Engineering, Institute of Building Structures, \\ Veveří 95, 60200 Brno, Czech Republic
}

\begin{abstract}
The article describes and verifies the possibility of applying secondary plastic materials to construction details such as flat roofs. The created element is a placement considered both in the area and in the finishing detail. The secure connection of the embedded element with the waterproofing layer is an integral part of the detail functionality. This is verified by a peeling resistance test at joints. Peel resistance is the tensile force required to completely separate the prepared joints. During testing, the test piece is pulled at constant speed until complete separation.
\end{abstract}

\section{Introduction}

The article describes and verifies a possibility of applying secondary plastic materials to construction details, such as flat roofs.

In terms of its position, an element can be placed in a flat part as well as in finishing details, e.g. in the attic. The secured connection of the embedded element with the waterproofing layer is an integral part of the detail functionality.

\section{Application of plastic in flat roofs}

Secondary materials, mostly of polymeric composition, can be a suitable element to substructures for technological systems in roof structures. Nowadays, insulators of higher strength are inserted, or spreading layers are created on the roof, where they may prevent smooth water drainage. Therefore, application of polymeric materials, potentially with additives, which guarantee all necessary parameters, seems to be the best solution.

\subsection{Production and testing of testing samples}

\subsubsection{Production of testing samples}

Testing boards were produced with dimensions of $150 \times 150 \times 15 \mathrm{~mm}$ from waste HDPE [1]. In order to improve heat, technical, and mechanical properties, other boards were

\footnotetext{
*Corresponding author: smolka.r@ffce.vutbr.cz
} 
produced with sawdust and blowing agents as additives. After measuring the coefficient of heat penetration, the boards were tested for peeling at connections [2-3].

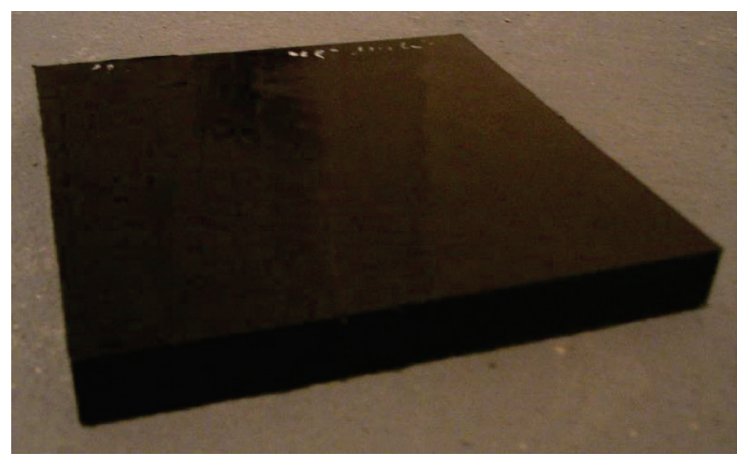

Fig. 1. Testing board - HDPE with added sawdust.

Four elements of bitumen sheets were applied on the testing board by fusing. Two on each side.

\subsubsection{Resistance from peeling at connections}

The test was performed in a laboratory of company Dehtochema bitumat-tn a.s. The testing method is designed for testing connections in mechanically fixed one-layer bitumen roofing.

Resistance to peeling is a tensile force necessary to complete separation of prepared connections. During testing, the testing body is pulled by a constant speed up to its complete separation.

The test was performed with the use of a testing tearing device LABORTECH 2.050, which is shown in Fig. 2. The device is equipped with continuous recording of force which corresponds with the distance of grips and it is able to keep balanced speed of separating the grips. The grip width may not be lower than $50 \mathrm{~mm}$. The speed of separating is defined as $100 \mathrm{~mm} \pm 10 \mathrm{~mm}$ per minute. The testing body is secured against displacement by an inserted stopper. Therefore, the displacement of the sample did not exceed $2 \mathrm{~mm}$.
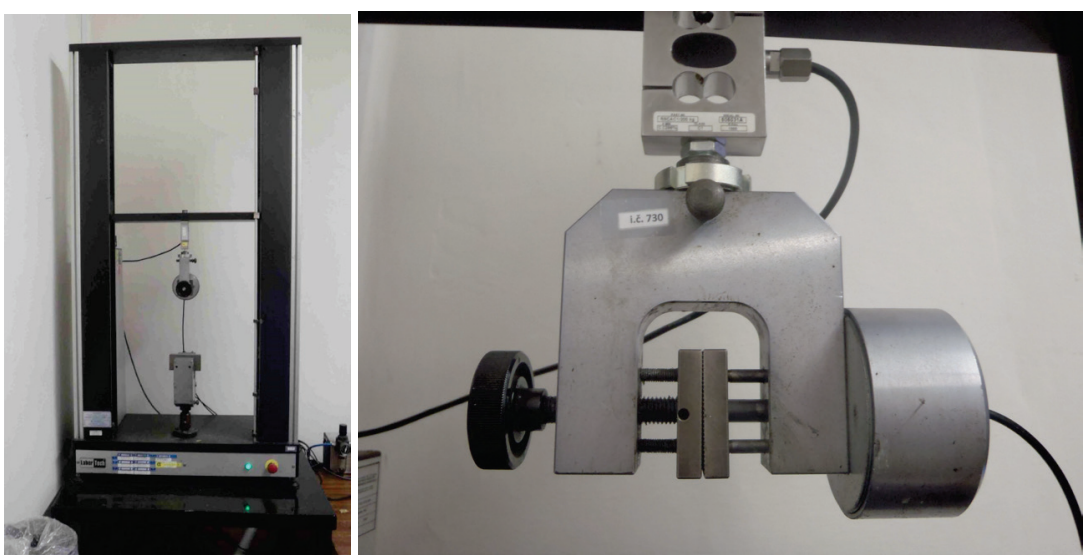

Fig. 2. Testing tearing device Labortech 2.050 and a detail of its upper grips. 
The testing samples for connections were tempered (left) for 48 hours at the temperature of $22^{\circ} \mathrm{C}-24^{\circ} \mathrm{C}$ under relative humidity of $60 \%$. Therefore, the tempering conditions complied with the standard conditions [3], i.e. 20 hours at the temperature $(23 \pm 2)^{\circ} \mathrm{C}$ and relative humidity of $(50 \pm 20) \%$.

\subsection{Used samples of bitumen sheets}

The following types of bitumen sheets were used for the measurements:

a) modified sheet - SBS - Skloelast extra, thickness $4 \mathrm{~mm}$, insertion - fiberglass, flexible at low temperature $-25^{\circ} \mathrm{C}$,

b) oxidised sheet - Extrasklobit PE, thickness $4 \mathrm{~mm}$, insertion - fiberglass, flexible at low temperature $0{ }^{\circ} \mathrm{C}$.

12 testing waterproofing stripes were prepared from two different bitumen sheets for the experiment. The bitumen sheets were cut into testing stripes of corresponding lengths, based on the type of test and prescribed width of $50 \mathrm{~mm} \pm 1 \mathrm{~mm}$. Each stripe was measured by a digital calipers before the test. The application of bitumen sheets was performed by flame fusing according to manufacturer's technical sheets. Subsequently, the sample was modified by rolling up to the phase when glut is made. The testing plastic bodies were not treated by any type of coating in order to improve adhesion.

Based on the test type, the lengths of $210 \mathrm{~mm}( \pm 1 \mathrm{~mm})$ and $270 \mathrm{~mm}( \pm 1 \mathrm{~mm})$ of individual bitumen stripes were selected; the lengths comply with the requirements of standards for the given test, i.e. $50 \mathrm{~mm}$ of the stripe is fixed to tearing grips of the device, $100 \mathrm{~mm}$ is the initial distance of tearing grips from the testing sample (connections), the remaining lengths $(60 \mathrm{~mm}$ and $120 \mathrm{~mm}$ ) are fused to the testing body.
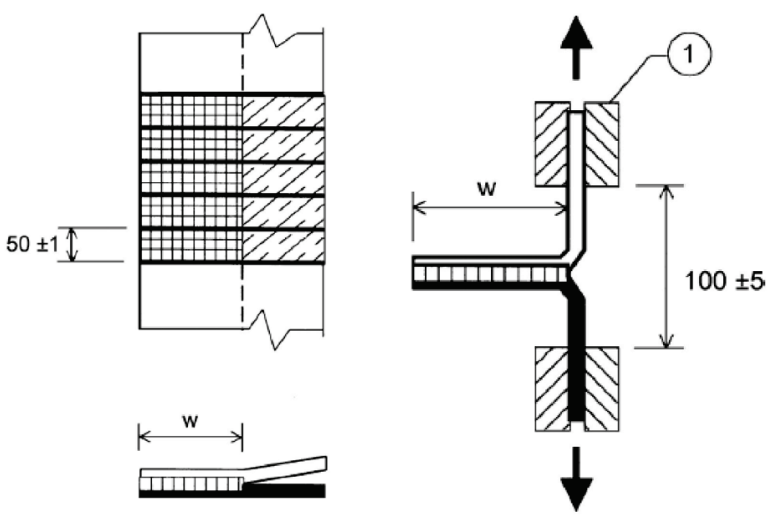

Fig. 3. Preparation of testing body according to standard; course of peeling test [3], 1 - tearing grips, $\mathrm{W}$ - connection length.

When calculating average resistance to peeling in connections in $[\mathrm{N}]$ for $50 \mathrm{~mm}$, the standard [3] states that the first and the last quarter of recorded data cannot be taken into account. For illustration, Table below shows all recorded values. Therefore, the testing evaluation omitted the data (first and last quarters) in accordance with the standard.

The following Table 1 describes individual testing samples and summarizes testing results (maximum tensile force). 
Table 1. Overview of tested samples.

\begin{tabular}{|c|c|c|c|c|c|c|}
\hline sample & plastic (type) & $\begin{array}{c}\text { sheet } \\
\text { type } \\
\text { application } \\
\text { method }\end{array}$ & $\begin{array}{c}\text { fusion } \\
\text { length } \\
{[\mathbf{m m}]}\end{array}$ & $\begin{array}{c}\text { maximum } \\
\text { force [N] }\end{array}$ & evaluation \\
\hline sample a01-60 & HDPE with sawdust & modified & flame fused & 60.00 & $\mathbf{1 5 2 . 5 0 9}$ & NO* $^{*}$ \\
\hline sample a02-60 & HDPE with sawdust & modified & flame fused & 60.00 & $\mathbf{2 3 4 . 3 0 3}$ & YES \\
\hline sample a03-60 & HDPE with sawdust & modified & flame fused & 60.00 & $\mathbf{3 7 6 . 7 1 0}$ & YES \\
\hline sample b01-60 & HDPE with sawdust & oxidised & flame fused & 60.00 & $\mathbf{4 8 5 . 6 1 6}$ & YES \\
\hline sample b02-60 & HDPE with sawdust & oxidised & flame fused & 60.00 & $\mathbf{3 6 7 . 2 5 9}$ & YES \\
\hline sample b03-60 & HDPE with sawdust & oxidised & flame fused & 60.00 & $\mathbf{4 2 1 . 0 9 4}$ & YES \\
\hline sample a01-120 & HDPE with sawdust & modified & flame fused & 120.00 & $\mathbf{3 9 8 . 2 8 2}$ & YES \\
\hline sample a02-120 & HDPE with sawdust & modified & flame fused & 120.00 & $\mathbf{3 7 5 . 3 4 1}$ & YES \\
\hline sample a03-120 & HDPE with sawdust & modified & flame fused & 120.00 & $\mathbf{4 8 2 . 5 5 3}$ & YES \\
\hline sample b01-120 & HDPE with sawdust & oxidised & flame fused & 120.00 & $\mathbf{4 8 4 . 9 0 0}$ & YES \\
\hline sample b02-120 & HDPE with sawdust & oxidised & flame fused & 120.00 & $\mathbf{4 0 5 . 9 0 8}$ & YES \\
\hline sample b03-120 & HDPE with sawdust & oxidised & flame fused & 120.00 & $\mathbf{4 0 7 . 4 7 2}$ & YES \\
\hline
\end{tabular}

The unsatisfactory sample in Tab. 1 marked NO* - Sample a01-60 was not activated by a hot flame before the fusing of the bitumen sheet. The fused sheet was just mechanically attached and rolled. Due to the imperfect application, the mentioned sample shows considerable range of values. A specific feature of fusing waterproofing materials is the presence of human factor. Uneven heating of elements, uneven fusing, poor rolling, and other technological faults may occur, which leads to imperfect application of an element.

The following Figure 4 of force courses shows the selected reference sample. The courses of measured values are crossed by a $4^{\text {th }}$ order polynomic trendline, and its equation is shown.

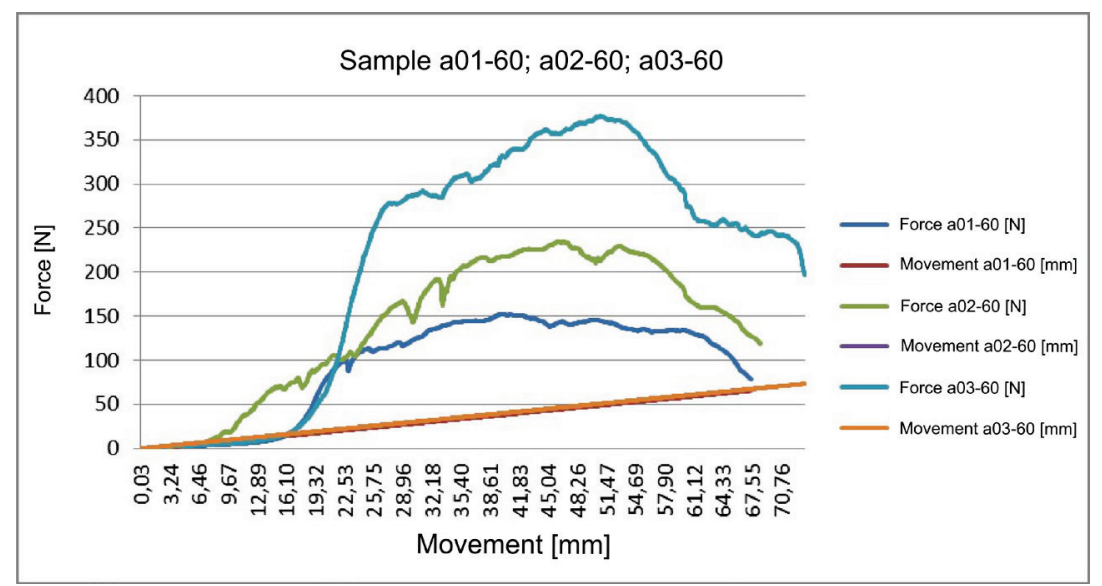

Fig. 4. Total of samples a01-60; a02-60; a03-60 - courses of forces.

Commonly reached values for tested waterproofing bitumen sheets during peeling tests in connections generally range between $150 \mathrm{~N}$ and $400 \mathrm{~N}$. 
During the testing the sheet either got damaged in the area around the insertion, or the lower part of the bitumen sheet from the bearing insertion was separated (Fig. 5). Therefore, the connection of the bitumen sheet and the secondary plastic material (HDPE) is stronger than the bitumen sheet material itself [4-6].

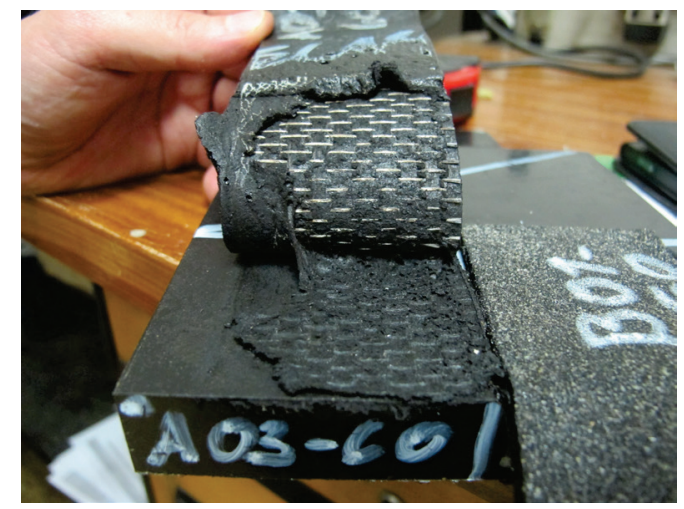

Fig. 5. Sample detail a03-60 - separation of bitumen material from the bearing insertion.

The test aimed to prove the feasibility of an idea to apply secondary plastic materials to roof structures under the waterproofing layers while still maintaining the required safety. It is necessary to perform the test with the final product. The test is only applied to a single type of secondary plastic material.

\section{Conclusion}

The main points of a new product for civil engineering were set. While maintaining the required flat roof slope gradient, the product should transfer even loading to heat insulating sublayers or be used as a substitute for a common heat insulator. In addition, it should allow simple and safe installation of waterproofing layers without changing the technological instructions. This product could be installed in new buildings (standard, passive, and energy-saving buildings) as well as in the existing buildings during reconstructions or modifications, mostly during modernisation works.

The following basic properties which the element should meet are selected:

- long life span,

- volume stability,

- tolerance to other materials (material corrosion),

- strength - resistance to impacts and stable loading,

- fast and all-year installation without technology change,

- meeting requirements for fire resistance,

- harmless to health,

- sound insulation.

The above mentioned properties are required for correct function and long-term life span of the designed product [4-6].

Materials from recycled plastic have a great potential for application in a wider scope of civil engineering. Their physical, mechanical, and chemical properties puts them in compositions where traditional heat insulation materials are used. Using a product from secondary materials results in a lower thickness of a structure, since no other waterproofing or spreading layers are necessary, while the requirements of technological standards, regulations, and legislation acts are met. A considerable advantage is lower financial costs for the construction. 
This paper has been worked out under the project No. LO1408 "AdMaS UP - Advanced Materials, Structures and Technologies", supported by Ministry of Education, Youth and Sports under the „National Sustainability Programme I”

\section{References}

1. L. Matejka, R. Smolka, patent EP 2159364 B1 Support structures for a doors threshold (Brno University of Technology, Munchen, 2012)

2. V. Duchacek, Polymers - production, properties, processing, applications (Institute of Chemical Technology in Prague, Prague, 2006)

3. ČSN EN 12316-1 (727638) Flexible sheets for waterproofing - Part 1: Bitumen sheets for roof waterproofing - Determination of peel resistance of joints (Prague, 2000)

4. J. Sobotka, AMR 1122, 65-69, 2015

5. R. Smolka; T. Petř́ŕček; P. Kacálek, AMM 824, 188-195 (2016)

6. P. Kacálek; R. Smolka; T. Petř́iček, AMR 1041, 288-292 (2014)

7. T. Petř́íček; P. Kacálek; R. Smolka, AMR 1041, 71-74 (2014) 